\title{
Anterior artery release, distraction and fusion (ARDF) for radiculopathy caused by a vertebral artery loop
}

\author{
Mazda Farshad $^{1}\left[\right.$. José Miguel Spirig ${ }^{1} \cdot$ Marco D. Burkhard ${ }^{1}$
}

Received: 15 February 2021 / Revised: 10 June 2021 / Accepted: 20 June 2021 / Published online: 25 June 2021

(c) The Author(s) 2021

\begin{abstract}
Background Anomalous vertebral artery (VA) with loop formation is a rare cause of cervical nerve root compression. Various techniques with anterior and posterior approaches have been described for surgical treatment once conservative treatments fail. We herein present a case treated with the new technique of anterior release, distraction and fusion (ARDF) and further provide an updated review of surgically managed VA loops in the subaxial spine.

Case description A 76-year-old female complained of a 6-year history of pulsating, shooting pain in her right arm to the thumb. After obtaining repeated MRI, the VA loop compressing the right-sided C6-nerve root was detected. A neurovascular decompression through ARDF which led to an indirect loop straightening was performed. The patient immediately improved after surgery and remained pain-free 1 year postoperative.

Conclusion Neural irritation due to VA loop formation is a rare cause of cervical radiculopathy. While various surgical strategies have been described, we believe that anterior and anterolateral approaches are the safest to yield neurovascular decompression. We described and documented ARDF (anterior VA release, intervertebral distraction and fusion) on a patient case. Level of evidence II (Diagnostic: individual cross-sectional studies with consistently applied reference standard and blinding).
\end{abstract}

Keywords ARDF · Vertebral artery $\cdot$ Artery Loop $\cdot$ Neurovascular $\cdot$ Cervical Spine

\section{Introduction}

Vertebral artery (VA) loop formation as an anatomic variation may seldomly cause neurovascular conflicts with adjacent cervical nerve roots [1]. Recognizing the abnormal course of the artery as a cause for these patients' radiculopathy may be challenging, as it can be overlooked on MRI. Management options for VA-related nerve root compression include conservative therapies and neurovascular decompression surgery [2]. We herein present a case with long-lasting painful sensory C6 radiculopathy that was successively treated by anterior artery release, distraction and fusion (ARDF), which led to a loop straightening and removal of the radical impingement. We further provide an updated review of surgically managed VA loops in the subaxial spine.

Mazda Farshad

mazda.farshad@balgrist.ch

1 Department of Orthopedic Surgery, Balgrist University Hospital, University of Zurich, Forchstrasse 340, 8008 Zurich, Switzerland

\section{Case report}

A 76-year-old female initially presented with a history of worsening right-sided neck pain for the past six to seven years. Her pain was sharp in nature with intermittent shooting sensations radiating to her right arm towards the thumb. Her symptoms were position-dependent with pain exacerbation when lying flat in the night. Lateral flexion of her neck to the affected side provoked and to the contralateral shoulder reduced pain. The patient had already tried multiple sessions of physiotherapy and acupuncture. She required regular analgesic medication with paracetamol for multiple years and started to use fentanyl patches in the further course. Beside a well-managed arterial hypertension and a substituted hypothyroidism, the patient was healthy and independently managed her daily duties. Her complaints were however significantly comprising her quality of life, which was reflected in a Neck Disability Index (NDI) of $30 \%$. In the clinical examination, the patient showed neither any sensomotor deficits nor myelopathic signs. Nerve root stress tests and deep tendon reflexes were normal. On X-ray, some degenerative changes including reduced intervertebral 
disc space $\mathrm{C} 5 / 6$ were noted. Beside some discrete foraminal narrowing of nerve roots C5 bilaterally and C6 and C7 on the right side, no clear neuroforaminal stenosis could be detected on MRI. Indirect CT-guided infiltration (1 ml dexamethasone $4 \mathrm{mg} / \mathrm{ml}$ and $1 \mathrm{ml}$ ropivacaine $0.2 \%$ ) of nerve root C6 on the right did not relieve any symptoms, nor did the
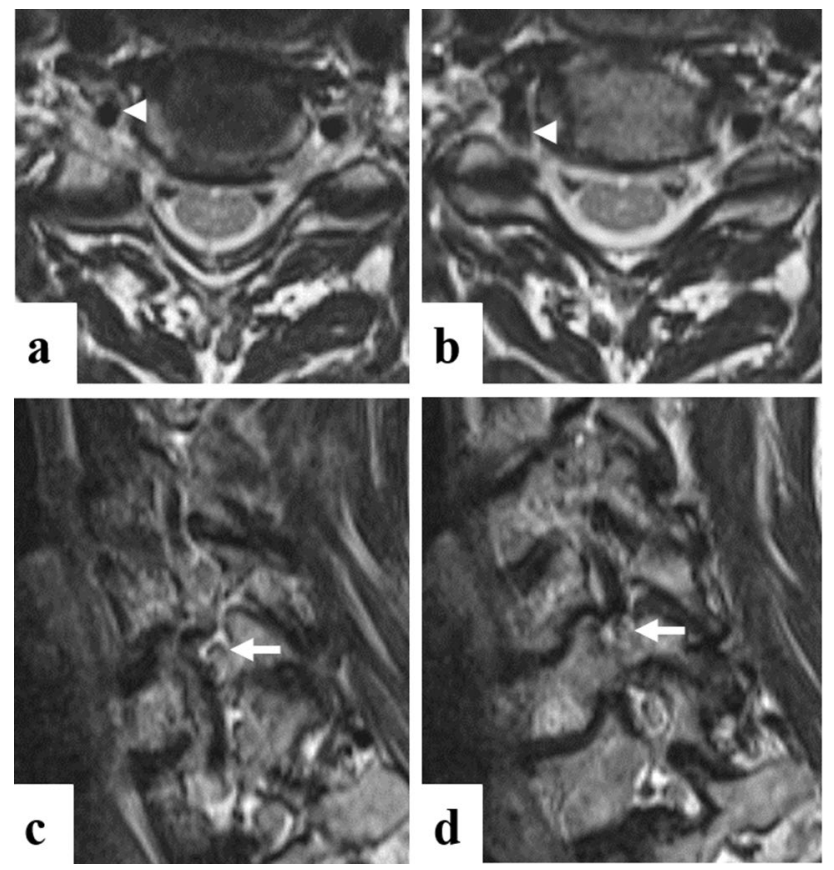

Fig. 1 a, b: Vertebral artery loop formation at level of the C6 nerve root on the right on axial T2-weighted MRI. B displays one slice $(3 \mathrm{~mm})$ more cranial than a. Arrowhead=vertebral artery $\mathbf{c}, \mathbf{d}$ : Neurovascular conflict vertebral artery with C6 nerve root on right sagittal oblique T2-MRI. D displays one slice more lateral to the right than C. Arrow $=$ nerve root $\mathrm{C} 6$ following $\mathrm{C} 7$ nerve root and facet joint infiltrations. Further evaluation with electroneuromyography could not reveal any signs of muscle denervation. On follow-up MRI, again no obvious neuroforaminal stenosis was detectable. However, a right-sided atypical tortuous course of the VA with a tight vessel loop formation at the segment $\mathrm{C} 5 / 6$ in proximity to the neuroforamen $\mathrm{C} 5 / 6$ on the right was visible (Fig. 1). Further $\mathrm{CT}$ angiography confirmed and better visualized the abnormal course of the VA in relation to the surrounding bony structures (Fig. 2).

Given her excruciating pain, a neurovascular decompression via "ARDF" of C5/6 was performed 18 months after first admission to our interdisciplinary spine unit.

\section{Surgical technique}

The patient was positioned supine in general anaesthesia. An anterior approach through a horizontal incision along the skin folds on the left was performed (equal to the approach used for anterior cervical discectomy and fusion). The platysma and subplatysmal planes were dissected. The carotid sheath was retracted laterally and the trachea and oesophagus medially. The correct level was confirmed with intraoperative fluoroscopy. The right longus colli muscle was laterally dissected off the vertebral bodies C5 and C6. The cervical spine at the level C5/6 was exposed including the transverse processes of $\mathrm{C} 5$ and $\mathrm{C} 6$ on the right. After central insertion of the pins into the vertebral bodies of $\mathrm{C} 5$ and C6 and temporary distraction over the pins, the intervertebral disc and posterior longitudinal ligament were removed. Under microscopic magnification, no compression on the nerve root could be identified at this point. Then, an uncectomy was performed on the right side using a high-speed
Fig. 2 Pre- and postoperative CT angiography and 1-year postoperative radiograph $\mathbf{a}$ : Preoperative sagittal view of vessel loop formation at level of neuroforamen C5/6 on the right. b: postoperative $\mathrm{CT}$ scan on postoperative day 1 showing the straightened course of the vertebral artery after neurovascular separation and restauration of the disc height with use of an interbody fusion cage. C: 1-year postoperative radiograph showed cage subsidence, although not clinically relevant. The remaining disc height may have prevented the reoccurrence of symptoms. Asterisk $=$ site of vertebral artery loop formation
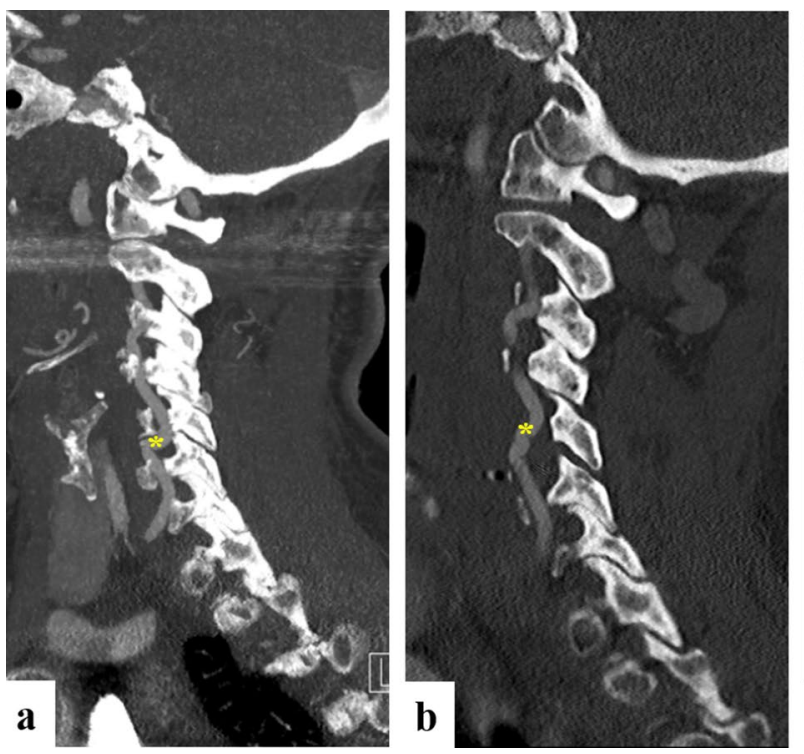
diamond burr. The VA was exposed, which showed a loop formation across the nerve root C6 causing a pulsatile compression of the nerve. Careful coagulation of the surrounding venous plexus was performed with electrocautery. After anterior deroofing of the transverse foramen of $\mathrm{C} 5$, the VA was mobilized along its course from $\mathrm{C} 5$ to $\mathrm{C} 6$, and the artery meticulously separated from the nerve root with a blunt dissector. With intervertebral distraction through the pins, the VA loop could be completely straightened and the neurovascular conflict dissolved (Fig. 3). Then, an 8-mm interbody cage (ACIS ProTi 360 Lordotic Standard, DePuy Synthes, Raynham MA) was inserted to restore disc height and maintain the straight course of the vessel (Fig. 4). Autograft bone from the removed uncinate process along with demineralized bone matrix $\left(0.5 \mathrm{~cm}^{3}\right.$ DBX Putty, DePuy Synthes, Raynham MA) was used to stimulate bony fusion. A drain was placed prior to a layered incision closure.

\section{Postoperative course}

The patient reported a complete resolution of her radicular pain immediately after the procedure. The straightened course of the VA was confirmed on the postoperative CT angiography on the first postoperative day (Fig. 2). One year after, the patient was very satisfied and remained pain free. Her NDI score decreased from 30 to 6\%. Although some cage subsidence was noted on the one-year postoperative radiograph, the pulsatile symptoms had resolved. The remaining intervertebral disc height caused by the intentional over distraction seems to have prevented the recurrence of the neurovascular conflict. Whether the VA
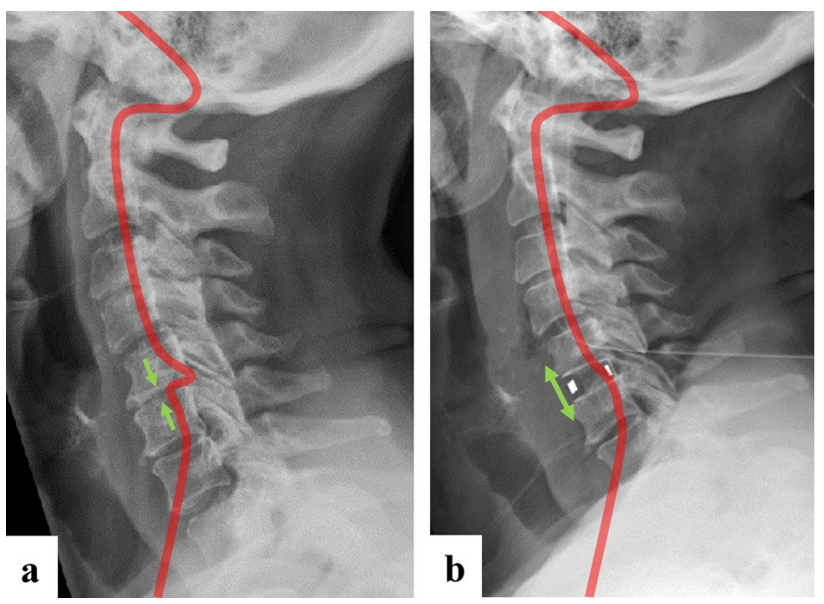

Fig. 4 Concept of ARDF. A) The artery loop has developed due to relative lengthening of the artery in relation to the collapsed intervertebral space $\mathrm{C} 5 / 6$. B) By restoring disc height through interposition of a large intervertebral cage at $\mathrm{C} 5 / 6$, the course of the artery is straightened and the neurovascular conflict dissolves

remained in an unchanged straight course, despite the cage subsidence, is unknown, but plausible. However, since all of the patient's symptoms had resolved until the one-year follow-up and further radiologic evaluations would not lead to any therapeutic consequence, we decided not to repeat the CTA.

\section{Discussion}

\section{Vertebral artery anatomy and variability}

Detailed knowledge of the anatomy of the V2 segment and awareness of its variability are crucial for safe surgery of
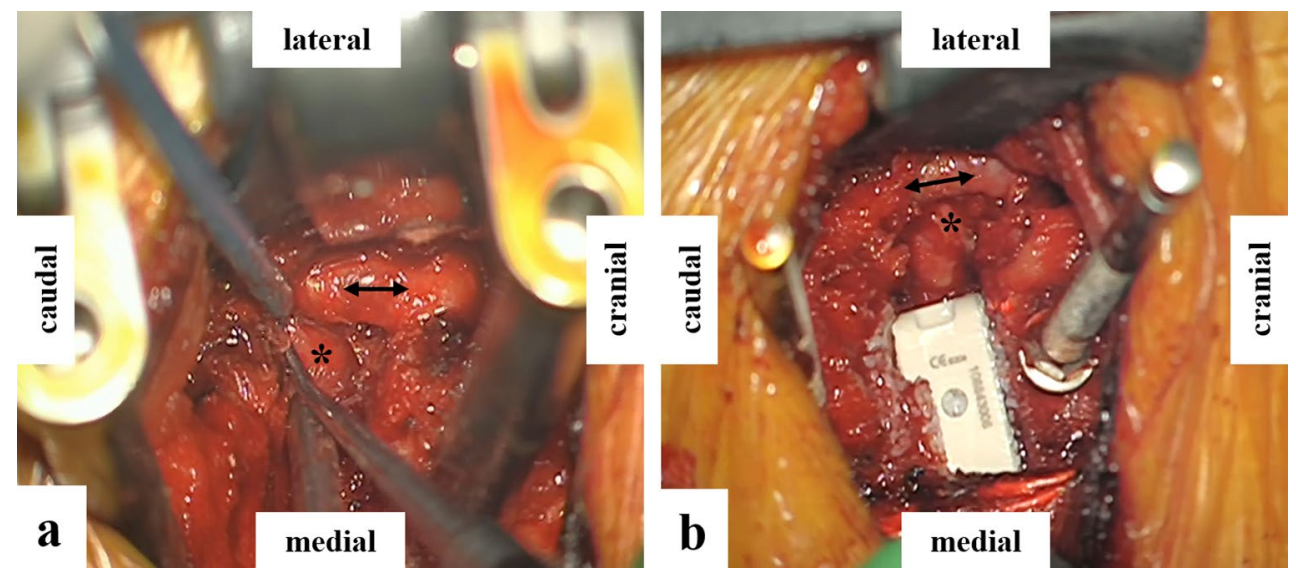

Fig. 3 Intraoperative images. A: Vertebral artery (double arrow) mobilization and separation from nerve root (asterisk). B: After insertion of a large interbody cage at C5-6 (asterisk), a straight course of the vertebral artery (double arrow) was ensured 
the subaxial spine. The VA course can be divided into four segments: V1 extending from the subclavian artery anterior to $\mathrm{C} 7$ to the entry point of the transverse foramen of C6, $\mathrm{V} 2$ through the transverse foramina of $\mathrm{C} 6$ to $\mathrm{C} 2, \mathrm{~V} 3$ from the superior aspect of the arch of $\mathrm{C} 2$ to the foramen magnum and the V4 intracranial course as it pierces the dura mater until unification at the basilar artery [3]. VA tortuosity has been reported to occur in 0.6 to $7.5 \%$ of the population $[4,5]$. Oga et al.[6] had classified the tortuosity in type 1 (straight), type 2 (mild tortuous), type 3 (loop formation) and type 4 (loop migration). VA tortuosity can be congenital or acquired, but the exact pathogenesis remains unclear [2, 6-8]. Some authors have speculated that haemodynamic stress due to arterial hypertension and atherosclerosis is the main cause, while others have associated it with degenerative changes $[6,9,10]$. In line with the observations by Sakaida et al. [10], the loop formation in the illustrated case aligned with severe disc narrowing, which led to the relative overlength of the VA.

\section{Clinical presentation and characteristics}

If VA loops become symptomatic, they typically present with sharp, shooting or pulsating radicular pain reminiscent of trigeminal neuralgia. Eksi et al. [2] reported VA tortuosity to be slightly more common in females than males (1.2:1 ratio) and most frequently become symptomatic in the fifth and sixth decades of life. C4/5 has been identified as the most common level of loop formation, followed by $\mathrm{C} 3 / 4$ and $\mathrm{C} 5 / 6$, with a side preference to the left. Our updated review of the literature of surgically treated VA loops in the subaxial spine (Table 1) found a more prominent female gender preference of $68 \%$ with a ratio of $2.2: 1$ and a side preference to the left in the same ratio (2.2:1) (Table 1).

\section{Diagnostic workup}

VA loop formations can easily be overlooked initially. However, other more common causes of radiculopathy must first be ruled out, because most VA loops remain silent. The VA's course should be determined on preoperative MRI for every cervical spine surgery to avoid intraoperative injury of the VA and thus its potentially disastrous outcomes. In patients with shooting pain refractive to conservative measures and no morphologic correlate on MRI, a thorough diagnostic workup is mandatory, and one must consider an undiagnosed VA loop-compressive radiculopathy. Although CT angiography was useful in evaluating the VA loop and its relation to the surrounding bony structures in our case, magnetic resonance angiography (MRA) is considered the firstline diagnostic tool in this regard, allowing a non-ionizing visualization of the neurovascular conflict [2]. Although some authors recommend angiographic VA evaluation of all patients undergoing cervical spine surgery, we believe that non-contrast MRI should remain the standard [2]. The benefits of MRA outweigh the risks and costs only in patients with a suspicion of symptomatic VA abnormality or injuries with VA involvement.

\section{Treatment strategies}

First-line management of symptomatic VA loops should always comprise physiotherapy and other conservative measures, given that several cases have successfully responded to this combination [5]. If conservative treatment fails, a wide panoply of surgical interventions has been described (Table 1). The primary surgical strategy usually comprises microvascular (MV) decompression.

\section{Anterior artery release, distraction and fusion (ARDF)}

In contrast to previous reports, the neurovascular conflict in the illustrated case was dissolved by straightening the VA loop through restauration of the collapsed intervertebral space between C5 and C6 (Fig. 4). However, one year postoperatively, cage subsidence was observed in the reported case with no clinical impact. In retrospect, anterior plating to augment the interbody fusion could have been considered to lower the risk of distraction loss [19]. It is also unclear which step of the surgical procedure (the artery release, the distraction, the interbody fusion or all of them together) can be attributed to the successful postoperative outcome of this patient. We believe, but cannot prove, that the sole neurovascular separation without distraction or fusion would likely have resulted in residual symptoms or recurrence of compressive radiculopathy in the presented case. However, this might be a theoretical debate because most patients present with some sort of degenerative changes that need surgical treatment of the according segment by anterior cervical decompression and fusion (ACDF).

\section{Anterolateral MV decompression by loop mobilization and separation from nerve root}

A majority of recent studies have utilized an anterolateral approach to mobilize the VA loop [1, 7, 8, 11-16]. The anterolateral approach allows a direct view and mobilization of the VA enclosed within the transverse processes [17, 18]. Distinct from other authors, Wood et al. [19] displayed the course of the artery by a direct lateral approach (lateral of the sternocleidomastoid muscle) with the neurovascular bundle retracted medially. 


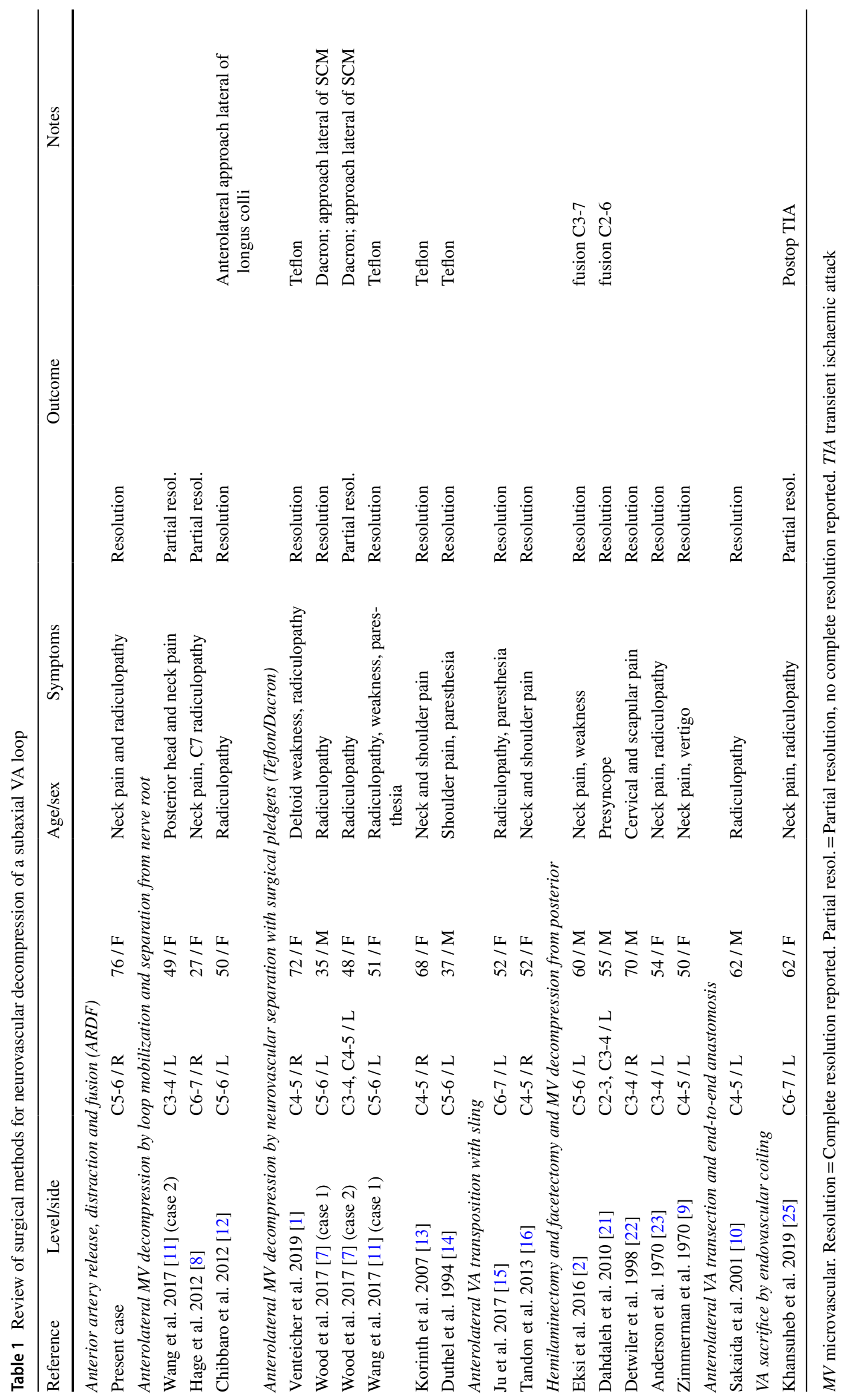




\section{MV decompression by neurovascular separation with surgical plugs}

Various authors have used additional strategies to detether and keep the mobilized VA away from the compressed nerve root, such as cushioning with soft polymer sponges made of Teflon [1, 7, 11, 13, 14]. Wood et al.[7] have utilized Dacron plugs, due to Teflon-associated granuloma formation, which was documented after the treatment of trigeminal neuralgia[20].

\section{Anterolateral VA transposition with sling}

Ju et al. [15] used an artificial dura mater tissue and set small screws into the adjacent vertebral bodies to suture the VA away from the nerve root. A similar technique was previously described by Tandon et al. [16] who utilized a human dermis allograft to sling the VA and suture it to the adjacent paraspinal muscles. Both authors reported complete resolution of symptoms after their procedure.

\section{Posterior neurovascular decompression via hemilaminectomy and facetectomy}

Initial reports have primarily utilized posterolateral approaches [2, 9, 21-23]. However, removal of posterior structures to expose the artery, particularly the facet joint, increases the risk of iatrogenic instability. Some authors have thus added fusion with lateral mass screws [2, 21]. Moreover, the higher risk of surgical site infections accompanied with the posterior approach must be considered [24]. In our opinion, this approach should be reserved for cases with multi-level VA loops and loops in the suboccipital region.

\section{Anterolateral VA transection and end-to-end anastomosis}

In extreme loop formations, the VA loop may be resected and reconstructed with end-to-end anastomosis, as proposed by Sakaida et al. [10] Notably, such a procedure is technically challenging and might bear a higher complication rate.

\section{VA sacrifice by endovascular coiling}

Recently, Khanusuheb et al. [25] have reported on a case in which the tortuous VA was sacrificed with endovascular coiling, because the initial microvascular decompression through a posterolateral approach could not succeed. However, the postoperative course was complicated by a transient ischaemic attack in the posterior fossa. This procedure should thus be regarded as last option, if at all.

\section{Conclusion}

Neural irritation due to VA loop formation is a rare cause of cervical radiculopathy. While various surgical strategies have been described, we believe that anterior and anterolateral approaches are the safest to yield neurovascular decompression. We described and documented the first case using the ARDF procedure.

Funding Open Access funding provided by Universität Zürich. No funds, grants or support from any organization were received for the submitted work.

Availability of data and material Not applicable.

\section{Declarations}

Conflicts of interest The authors have no conflicts of interest to declare that are relevant to the content of this article.

Ethical approval Ethical approval was obtained from the cantonal ethics committee of Zurich (req-2021-00150.

Consent to participate Prior to surgery, a written and informed consent was obtained from the patient reported.

Consent for publication The patient was informed and agreed that case-related information and images will be submitted for publication.

Open Access This article is licensed under a Creative Commons Attribution 4.0 International License, which permits use, sharing, adaptation, distribution and reproduction in any medium or format, as long as you give appropriate credit to the original author(s) and the source, provide a link to the Creative Commons licence, and indicate if changes were made. The images or other third party material in this article are included in the article's Creative Commons licence, unless indicated otherwise in a credit line to the material. If material is not included in the article's Creative Commons licence and your intended use is not permitted by statutory regulation or exceeds the permitted use, you will need to obtain permission directly from the copyright holder. To view a copy of this licence, visit http://creativecommons.org/licenses/by/4.0/.

\section{References}

1. Venteicher AS, Quddusi A, Coumans JV (2019) Anterolateral approach for a cervical nerve root compression syndrome due to an ectatic vertebral artery. Oper Neurosurg (Hagerstown) 17:E29e32. https://doi.org/10.1093/ons/opy282

2. Eksi MS, Toktas ZO, Yilmaz B, Demir MK, Ozcan-Eksi EE, Bayoumi AB, Yener Y, Akakin A, Konya D (2016) Vertebral artery loops in surgical perspective. Euro Spine J : Off Pub Euro Spine Soc, Euro Spinal Deform Soc, Euro Sect Cerv Spine Res Soc 25:4171-4180. https://doi.org/10.1007/s00586-016-4691-1

3. Heary RF, Albert TJ, Ludwig SC, Vaccaro AR, Wolansky LJ, Leddy TP, Schmidt RR (1996) Surgical anatomy of the vertebral arteries. Spine 21:2074-2080. https://doi.org/10.1097/00007632199609150-00004 
4. Park SB, Yang HJ, Lee SH (2012) Medial loop of v2 segment of vertebral artery causing compression of proximal cervical root. J Korean Neurosurg Soc 52:513-516. https://doi.org/10.3340/jkns. 2012.52.6.513

5. Paksoy Y, Levendoglu FD, Ogün CO, Ustün ME, Ogün TC (2003) Vertebral artery loop formation: a frequent cause of cervicobrachial pain. Spine 28:1183-1188. https://doi.org/10.1097/01.Brs. 0000067275.08517 .58

6. Oga M, Yuge I, Terada K, Shimizu A, Sugioka Y (1996) Tortuosity of the vertebral artery in patients with cervical spondylotic myelopathy. Risk factor for the vertebral artery injury during anterior cervical decompression. Spine 21:1085-1089. https://doi.org/ 10.1097/00007632-199605010-00019

7. Wood L, Czyz M, Forster S, Boszczyk BM (2017) The diagnosis and management of a vertebral artery loop causing cervical radiculopathy. Euro Spine J : Off Pub Euro Spine Soc, Euro Spinal Deform Soc, Euro Sect Cerv Spine Res Soc. https://doi.org/10. 1007/s00586-017-5123-6

8. Hage ZA, Amin-Hanjani S, Wen D, Charbel FT (2012) Surgical management of cervical radiculopathy caused by redundant vertebral artery loop. J Neurosurg Spine 17:337-341. https://doi. org/10.3171/2012.7.Spine123

9. Zimmerman HB, Farrell WJ (1970) Cervical vertebral erosion caused by vertebral artery tortuosity. Am J Roentgenol Radium Ther Nucl Med 108:767-770. https://doi.org/10.2214/ajr.108.4. 767

10. Sakaida H, Okada M, Yamamoto A (2001) Vascular reconstruction of a vertebral artery loop causing cervical radiculopathy and vertebrobasilar insufficiency. Case report J Neurosurg 94:145149. https://doi.org/10.3171/spi.2001.94.1.0145

11. Wang DD, Burkhardt JK, Magill ST, Lawton MT (2017) Anterior transposition of anomalous tortuous vertebral artery causing cervical radiculopathy: a report of 2 cases and review of literature. World Neurosurg 101:289-295. https://doi.org/10.1016/j.wneu. 2017.01.129

12. Chibbaro S, Mirone G, Yasuda M, Marsella M, Di Emidio P, George B (2012) Vertebral artery loop-a cause of cervical radiculopathy. World Neurosurg 78:375.e311-373. https://doi.org/10. 1016/j.wneu.2011.12.002

13. Korinth MC, Mull M (2007) Vertebral artery loop causing cervical radiculopathy. Surg Neurol 67:172-173. https://doi.org/10. 1016/j.surneu.2006.03.047

14. Duthel R, Tudor C, Motuo-Fotso MJ, Brunon J (1994) Cervical root compression by a loop of the vertebral artery: case report. Neurosurgery 35:140-142. https://doi.org/10.1227/00006123199407000-00022

15. Ju CI, Kim JM, Kim JG, Kim SW, Lee SM (2017) A new sling technique in cervical radiculopathy caused by vertebral artery loop compression. World Neurosurg 104:1049.e1011-1049.e1015. https://doi.org/10.1016/j.wneu.2017.05.090
16. Tandon A, Chandela S, Langer D, Sen C (2013) A novel sling technique for microvascular decompression of a rare anomalous vertebral artery causing cervical radiculopathy. Neurosurg Focus 35:E2. https://doi.org/10.3171/2013.6.Focus1339

17. Verbiest H (1969) Anterolateral operations for fractures and dislocations in the middle and lower parts of the cervical spine. Report of a series of forty-seven cases. J Bone Joint Surg Am 51:1489-1530

18. Bruneau M, Cornelius JF, George B (2006) Microsurgical cervical nerve root decompression by anterolateral approach. Neurosurgery 58:ONS108-113; discussion ONS108-113. doi: https://doi. org/10.1227/01.Neu.0000193521.98836.C5

19. Frank RM, Bernardoni ED, Cotter EJ, Verma NN (2017) Anatomic acromioclavicular joint reconstruction with semitendinosus allograft: surgical technique. Arthrosc Tech 6:e1721-e1726. https://doi.org/10.1016/j.eats.2017.06.045

20. Premsagar IC, Moss T, Coakham HB (1997) Teflon-induced granuloma following treatment of trigeminal neuralgia by microvascular decompression. Report Two Cases J Neurosurg 87:454-457. https://doi.org/10.3171/jns.1997.87.3.0454

21. Dahdaleh NS, Albert GW, Hasan DM (2010) Multiple symptomatic vertebral artery loops treated with posterior cervical fusion. J Clin Neurosci 17:788-790. https://doi.org/10.1016/j.jocn.2009. 10.004

22. Detwiler PW, Porter RW, Harrington TR, Sonntag VK, Spetzler RF (1998) Vascular decompression of a vertebral artery loop producing cervical radiculopathy. Case Rep J Neurosurg 89:485-488. https://doi.org/10.3171/jns.1998.89.3.0485

23. Anderson RE, Shealy CN (1970) Cervical pedicle erosion and rootlet compression caused by a tortuous vertebral artery. Radiology 96:537-538. https://doi.org/10.1148/96.3.537

24. Fehlings MG, Smith JS, Kopjar B, Arnold PM, Yoon ST, Vaccaro AR, Brodke DS, Janssen ME, Chapman JR, Sasso RC, Woodard EJ, Banco RJ, Massicotte EM, Dekutoski MB, Gokaslan ZL, Bono CM, Shaffrey CI (2012) Perioperative and delayed complications associated with the surgical treatment of cervical spondylotic myelopathy based on 302 patients from the AOSpine North America Cervical Spondylotic Myelopathy Study. J Neurosurg Spine 16:425-432. https://doi.org/10.3171/2012.1.Spine11467

25. Khansuheb MZ, Kouznetsov E, Manchak M, Durrani Q, Drofa A (2019) Vertebral artery sacrifice: novel strategy in treatment of vertebral artery loop. World Neurosurg 134:280-283. https://doi. org/10.1016/j.wneu.2019.10.068

Publisher's Note Springer Nature remains neutral with regard to jurisdictional claims in published maps and institutional affiliations. 